\title{
Biodegradability and Tissue Reaction of Random Copolymers of L-Leucine, L-Aspartic Acid, and L-Aspartic Acid Esters
}

\author{
K. W. MARCK and CH. R. H. WILDEVUUR, Department of \\ Experimental Surgery, University Hospital, Groningen, The Nether- \\ lands, and W. L. SEDEREL, A. BANTJES, and J. FEIJEN, \\ Department of Chemical Technology, Twente University of Technology, \\ Enschede, The Netherlands
}

\begin{abstract}
Summary
A series of copoly ( $\alpha$-amino acids) with varying percentages of hydrophilic (L-aspartic acid) and hydrophobic monomers (L-leucine, $\beta$-methyl-L-aspartate, and $\beta$-benzyl-L-aspartate) were implanted subcutaneously in rats and the macroscopic degradation behavior was studied. Three groups of materials $(A, B, C)$ with different ranges of hydrophilicity were distinguished: A) hydrophobic materials showed no degradation after 12 weeks; B) more hydrophilic materials revealed a gradual reduction in size of the samples, but were still present after 12 weeks; and C) hydrophilic copolymers disappeared within $24 \mathrm{hr}$.

The tissue reactions caused by the materials of group $A$ resembled that of silicone rubber, whereas those of group B showed a more cellular reaction.
\end{abstract}

\section{INTRODUCTION}

The study of the in vivo degradation of polymers is a prerequisite for the selection of implant materials for different purposes. For most applications, biodegradation of polymers and the usual concomitant deterioration of the mechanical properties have to be avoided. However, some specific applications of polymers rather require a controlled in vivo degradation process. This is relevant, for instance, for bioadhesives, ${ }^{1,2}$ suture materials, ${ }^{3,4}$ and carriers for controlled drug release. ${ }^{5}$

(C) 1977 by John Wiley \& Sons, Inc. 
Until now, most synthetic biodegradable polymers have been homopolymers; consequently, the rate of biodegradation could be varied only by changing molecular weights. For wide application of biodegradable materials, a better control of the rate of in vivo degradation is needed to meet the specific requirements. In principle, the use of copolymers with different compositions offers a possibility to establish an optimal rate of biodegradation.

In this study, copoly ( $\alpha$-amino acids) with various degrees of hydrophilicity, obtained by varying the percentages of hydrophilic (L-aspartic acid) and hydrophobic monomers (L-leucine, $\beta$-methyl-Laspartate, and $\beta$-benzyl-L-aspartate), were implanted subcutaneously in rats. It was hypothesized that variation in hydrophilicity could correlate with the rate of biodegradation of these poly ( $\alpha$-amino acids). The tissue reaction caused by the materials after implantation was histologically studied and compared with that of siliconc rubber (SR).

\section{MATERIALS AND METHODS}

A series of $\operatorname{poly}(\alpha$-amino acids) with varying compositions of L-leucine (Leu), $\beta$-benzyl-L-aspartate (AspOBz), $\beta$-methyl-L-aspartate (AspOMe), and L-aspartic acid (AspOH) were studied and compared with silicone rubber (SR, Silastic sheeting, $100 \mu$, Dow Corning). Random copolymers of L-leucine and $\beta$-benzyl-L-aspartate (Leu/AspOBz, I) were prepared as described previously. ${ }^{6}$ Copolymers of L-leucine, $\beta$-benzyl-L-aspartate, and $\beta$-methyl-L-aspartate (Leu/AspOBz/AspOMe, II) were obtained from I by treatment with methanol and a catalytic amount of concentrated sulfuric acid. This procedure is known to give no chain scission. ${ }^{7}$

Hydrophilic copolymers of L-leucine, $\beta$-benzyl-L-aspartate, and L-aspartic acid (Leu/AspOBz/AspOH, III) were obtained from polymers I by treatment with hydrogen bromide in chloroform under anhydrous conditions. Under these conditions, no racemization or degradation occurred. The excess hydrogen bromide was removed by a stream of nitrogen gas for 1-2 hr. The polymers were dissolved in pyridine and precipitated in water, then filtered and washed with water. The amount of ionic groups in these polymers was determined by potentiometric titration. ${ }^{6}$ 
Films of I were obtained by casting solutions of I in chloroform $(4 \% \mathrm{w} / \mathrm{v})$ on a glass plate using a doctor's knife. This procedure was repeated until the desired thickness of the film was obtained. Films of II were cast in a similar way using tetrahydrofuran solutions $(4 \% \mathrm{w} / \mathrm{v})$, and films of III were obtained after a single casting procedure using warm pyridine solutions $(5 \% \mathrm{w} / \mathrm{v})$. The dried films were peeled off the glass plate after immersion in deionized water. After repeated washings, the films were dried on filter paper. Disks of the materials were stamped from the films. Disks from copolymers III were stamped under wet conditions because dry films are brittle. Films of neutralized copolymers of III (Leu/AspOBz/AspONa, IV) were obtained by treating films of III with a sodium bicarbonate solution for several hours. Disks were obtained in the same manner as mentioned before. All the disks had a diameter of $6 \mathrm{~mm}$ and a thickness of $50-100 \mathrm{~m} \mu$.

A survey of the number of samples and the compositions of the tested materials, according to the various implantation periods, is given in Table $\mathrm{I}$. All the materials were sterilized in ethylene oxide at $29^{\circ} \mathrm{C}$ for $3 \mathrm{hr}$ except material III $(0.60)$, which was sterilized at $48^{\circ} \mathrm{C}$ for $1 \mathrm{hr}$ and $50 \mathrm{~min}$. After the sterilization, no changes in the chemical structure of the materials were detected by infrared spectroscopy.

Sixty-eight male Wistar rats weighing 200-300 g were anesthetized with ether and chloral hydrate (80-120 $\mathrm{mg}$, intraperitoneally). Their backs were shaved, depilated, and cleaned with iodine. Under sterile conditions, three incisions of ca. $1 \mathrm{~cm}$ were made on each side of the back. Subcutaneous pockets were prepared by blunt dissection, and different combinations of materials were then implanted. After implantation of the samples, the incisions were closed with interrupted sutures (4-0 atraumatic silk).

The animals were sacrificed $1,2,3$, or 4 days, and $1,2,4,6$, or 12 weeks after implantation (Table I). The skin of the back was incised along the midline and the subcutaneous tissue was prepared free to each side. The macroscopic aspects of the implantation site were investigated for tissue reaction and signs of disintegration of the materials. The tissue in these areas was harvested for histological investigation and fixed in $8 \%$ formalin. Paraffin sections of 4-5 $\mathrm{m} \mu$ were made and stained with hematoxylin and eosin. The 


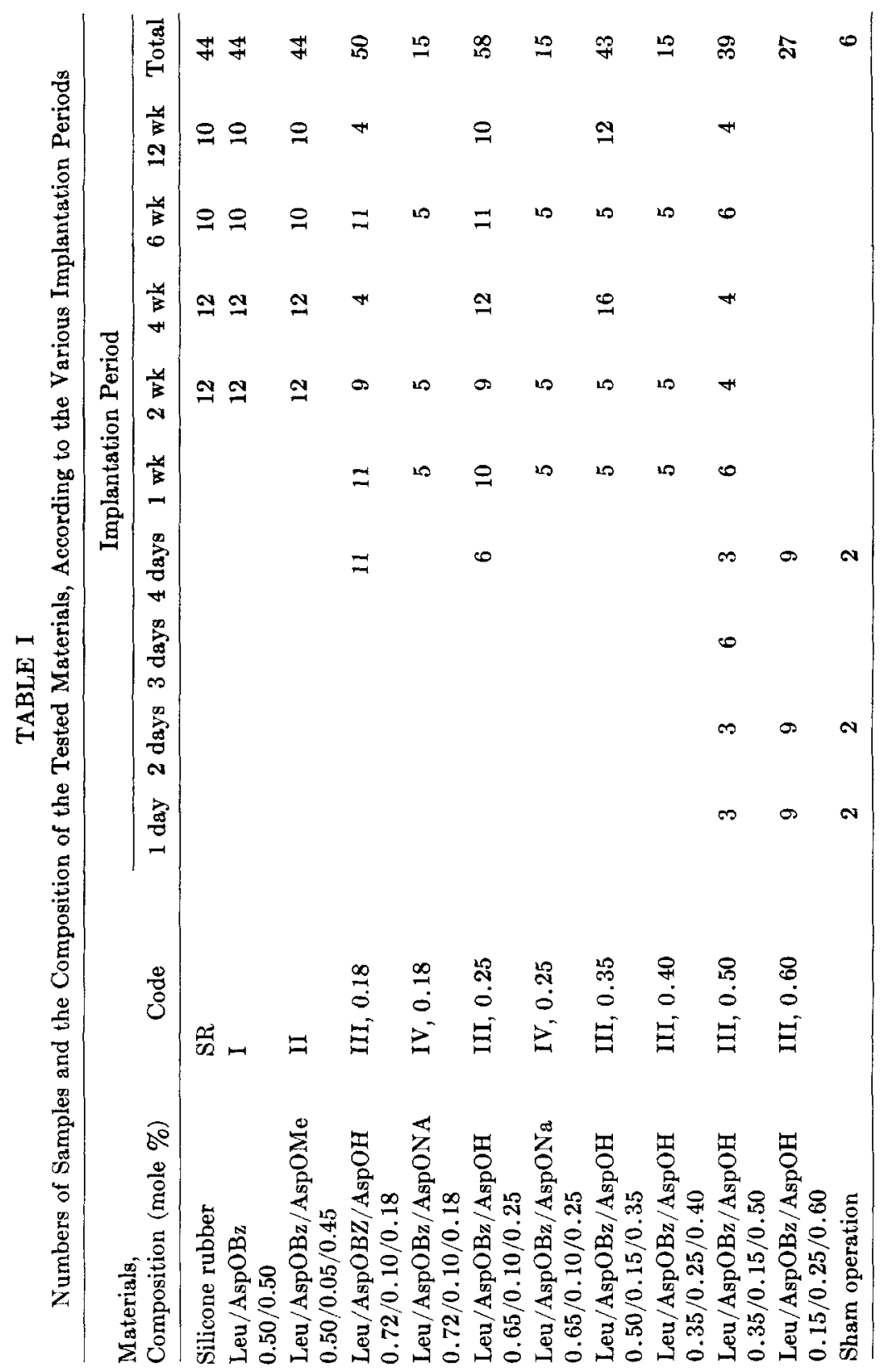


histological evaluation consisted of a description of the tissue reaction and the determination of the capsula thickness of the materials $1,2,3$, and 4 days or $1,2,4,6$, or 12 weeks after implantation.

The circumference and the surface area of a capsula were determined by using a graticule in an ocular of a microscope. A relative value for the capsula thickness was then obtained by dividing the value for the surface area by that of the circumference. The thicknesses of fibrous capsulae around the disks of materials I, II and SR at different time intervals were compared. A statistical analysis (Student's $t$-Test) was used to determine any significant differences in the thicknesses.

\section{RESULTS}

\section{Biodegradability : Macroscopic Observations}

Alterations in form and size of the various materials at several time intervals are schematically given in Figure 1. This scheme is based on a number of observations, corresponding with the number of implants as shown in Table I. Three groups can be distinguished.

Group A. Samples of these materials were found without any alteration in form and size: silicone rubber (SR), Leu/AspOBz (I), and Leu/AspOBz/AspOMe (II).

Group $B$. Samples of these materials became irregular and decreased in size in the course of weeks: copolymers III with a relatively low mole percentage $(0.18,0.25$, and 0.35$)$ of $\mathrm{L}$-aspartic acid and the corresponding sodium salt derivatives of III, the copolymers IV $(0.18$ and 0.25$)$.

Group C. These samples could not be detected $24 \mathrm{hr}$ after implantation: copolymers III with a relatively high mole percentage $(0.50$ and 0.60$)$ of $L$-aspartic acid and copolymer III $(0.40)$, samples of which could not be detected 1 week after implantation (first observation was 1 week after implantation).

The samples of group A were covered by a thin and smooth layer without any reaction in the surrounding tissue. The samples of group B were irregular, shrivelled up, and decreased in size in a few cases within 1 week and in most cases within 2 weeks (see Fig. 1). A further decrease was observed in the following weeks, but all samples were still present after the longest observation period of 6 or 12 


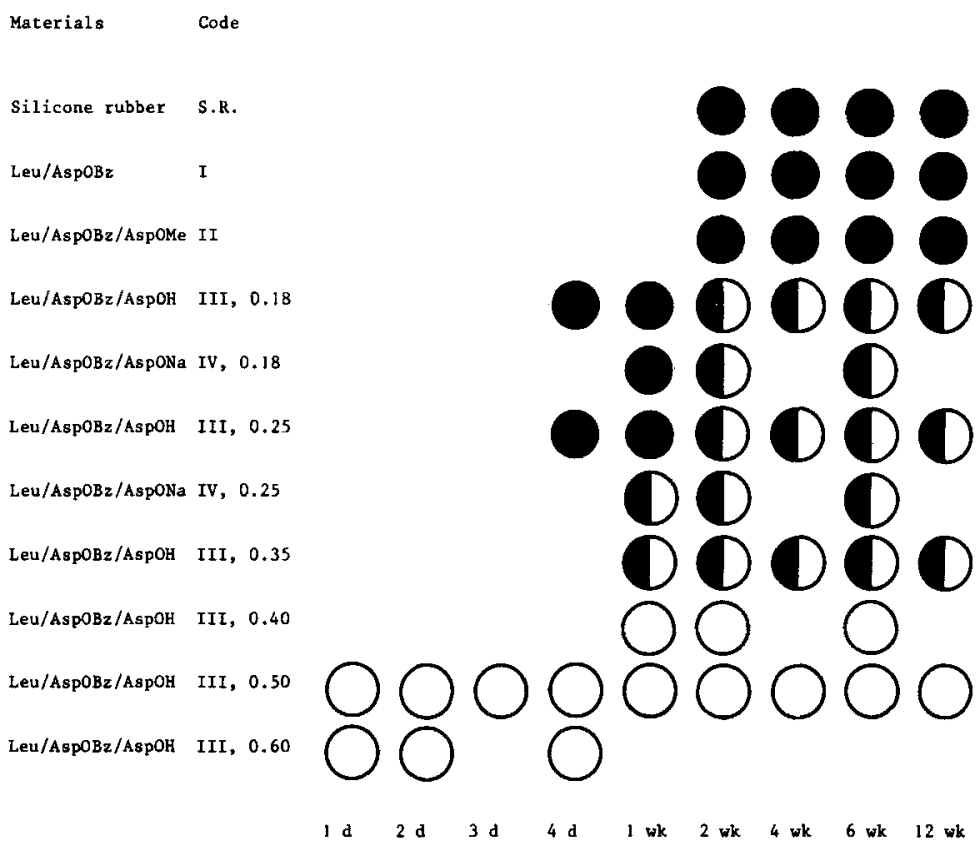

Fig. 1. Schematic representation of the effect of implantation after various periods on the size of the samples of the tested materials at harvesting time: (O) no change in size of the sample; (O) reduction in size of the sample; (O) sample cannot be detected. Each symbol is based on a number of observations, corresponding with the number of implants as shown in Table I.

weeks. They were then covered by a thicker and more wrinkled layer than the samples of group A in the first 2 weeks. Seven out of 10 samples of Leu/AspOBz/AspONa (IV, 0.25) showed some hyperemia and hemorrhage in the capsula and in the surrounding tissue. The occurrence of these phenomena was significantly more frequent ( $\chi^{2}$ test, $p=0.005$ ) than with the other materials (6 out of 54) of group B. In this period, the samples of Leu/AspOBz/AspONa (IV, 0.25) and, to a lesser extent (IV, 0.18), both hydrophilic by nature, were clearly swollen up; this was not observed in the corresponding acid precursors (III, 0.18 and 0.25 ).

The samples of group $\mathrm{C}$ were not detectable at the first observation after $24 \mathrm{hr}$. This was attended by edema and hemorrhage in the first week which occurred significantly more frequently than in sham- 
operated pockets ( $\chi^{2}$ test, $\left.p=0.005\right)$. The samples of Leu/AspOBz/ AspOH (III, 0.40), investigated only after 7 days, showed the same pattern as (III, 0.50) and (III, 0.60).

\section{Biocompatibility : Microscopic Evaluation}

\section{Group A}

Two weeks after implantation, the samples were surrounded by a cell-rich capsula; outside the capsula, newly formed connective tissue showed hyperemia and proliferation of capillaries. The capsula consisted of two different layers: an outer layer of fibroblasts and a frequently interrupted inner layer of polyhedric cells, $2-6$ cells thick. Four and 6 weeks after implantation, the hyperemia decreased and the capsula became thicker and more separated from the surrounding tissue. Twelve weeks after implantation, the capsula was more celldeprived and consisted mostly of fibroblasts, some macrophages, monocytes, and foreign-body giant cells (Fig. 2). The polyhedric cells were still present, but the amount decreased while the hyper-

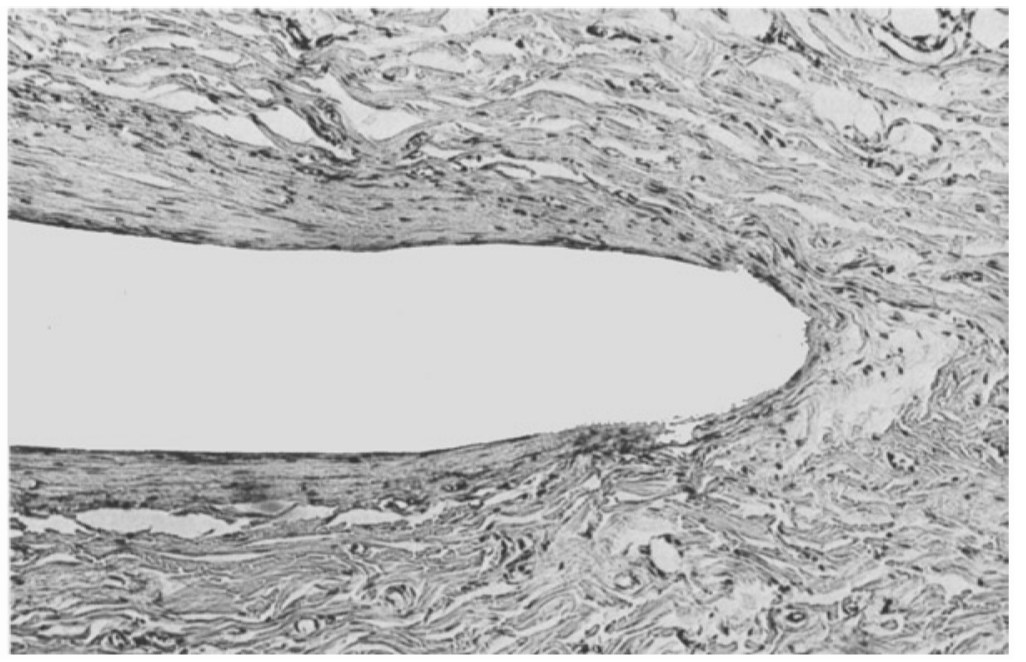

Fig. 2. Microscopic examination $(144 \times)$ of a biopsy taken after 12 weeks of Leu/AspOBz/AspOMe. The capsula is of irregular thickness, rather celldeprived and composed of fibroblasts. 
vascularity of the capsula diminished. The formation of collagen in the capsula increased with time.

Eosinophilic leukocytes were rarely seen at any interval. The capsula of silicone rubber (Fig. 3a) contains a more continuous inner layer of polyhedric cells than the capsula of the poly ( $\alpha$-amino acids) (Fig. $3 b)$. The poly ( $\alpha$-amino acids) are mostly fixed to the capsula, while silicone rubber is loose from it. Various thicknesses of the capsula of the materials of group A at various time intervals are shown in Table II. It is apparent from Table II that the thicknesses of the capsula of silicone rubber and Leu/AspOBz/AspOMe (II) do not differ significantly between 4 and 6 weeks, while Lcu/AspOBz (I) shows a significant $(p=0.025)$ increase between 4 and 6 weeks, but not between 6 and 12 weeks. The capsula of the poly ( $\alpha$-amino acids) after 4 weeks are thinner than those of silicone rubber $(p=0.025)$. However, this difference is not significant at 12 weeks after implantation.

\section{Group B}

At first observation, the materials of this group were fragmentated. At 4 and 7 days after implantation, several polymorphonuclear leukocytes, mesenchymal cells, and fibrin were seen in the pocket. Edema, hyperemia, proliferation of capillaries, many fibroblasts, and a few eosinophilic leukocytes and lymphocytes were observed in the surrounding tissue. From day 7 , encapsulation started by closely stratified fibroblasts around the samples. No differences in tissue reaction were seen between $\mathrm{Leu} / \mathrm{AspOBz} / \mathrm{AspOH}$ (III, 0.18), (III, 0.25), and Leu/AspOBz/AspONa (IV, 0.18). A more frequent and extensive hyperemia around the capsula was observed in the case of $\mathrm{Leu} / \mathrm{AspOBz} / \mathrm{AspONa}(\mathrm{IV}, 0.25) 1$ and 2 weeks after implantation. However, this difference in tissue reaction disappeared after 6 weeks. Two weeks after implantation, a great variation was seen in number of eosinophilic leukocytes and in the extent of lymphocytic infiltrates, more related to individual animals than to different materials. Six weeks after implantation, more frequent and extensive infiltrates of lymphocytes were found, accompanied by several plasma cells and numerous eosinophilic leukocytes in and outside the capsula (Fig. 4). This reaction was not as apparent for Leu/AspOBz/AspOH (III, 0.35). Six and 12 weeks after implantation, a similar encapsulation 


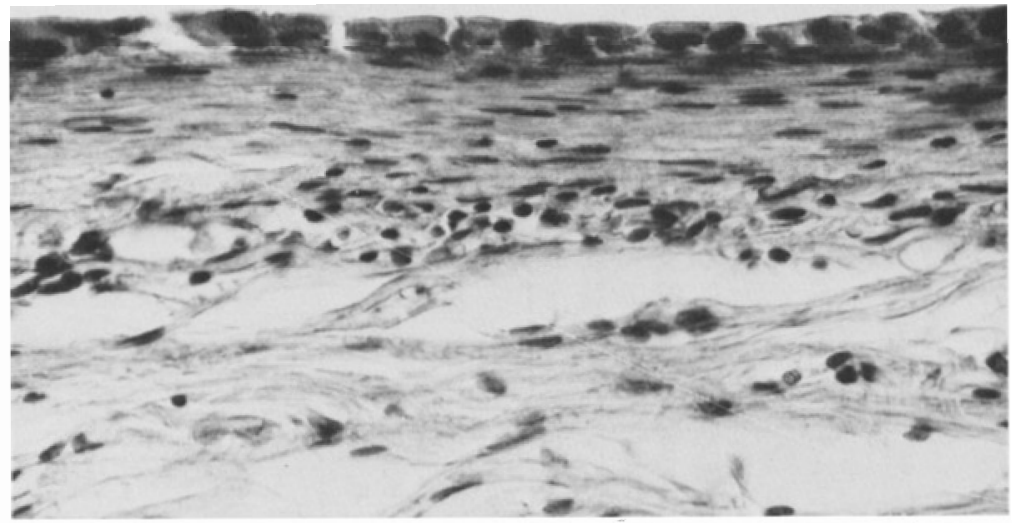

(a)

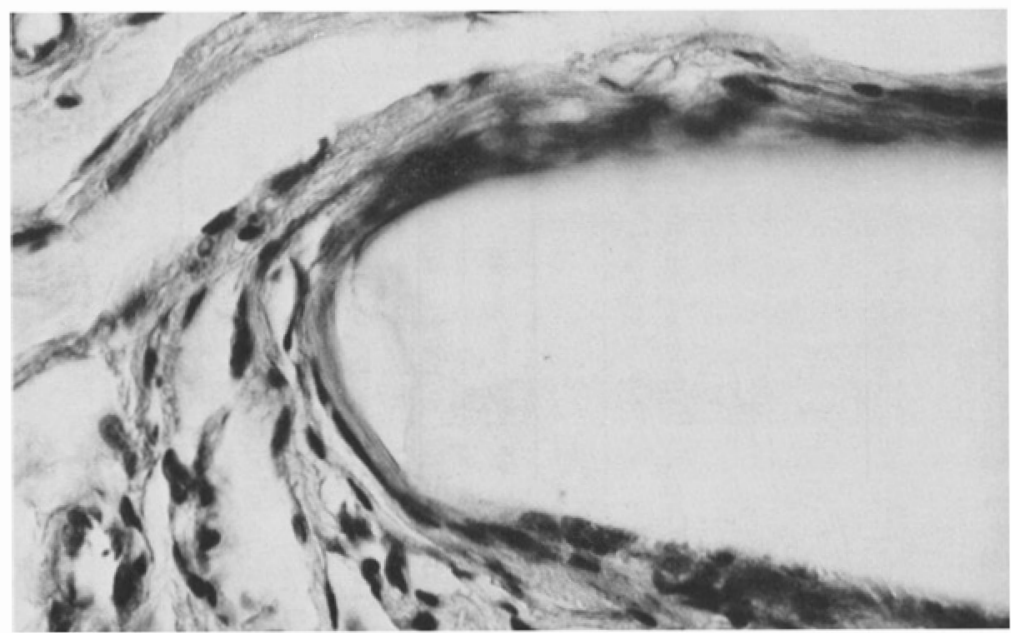

(b)

Fig. 3. Microscopic examination $(575 \times)$ of biopsies taken after 12 weeks of (a) silicone rubber and (b) Leu/AspOBz/AspOMe. In (a) the capsula is composed of a continuous layer of polyhedric cells and an outer layer of predominantly fibroblasts. In (b) the capsula is composed of a discontinuous inner layer of polyhedric cells. 


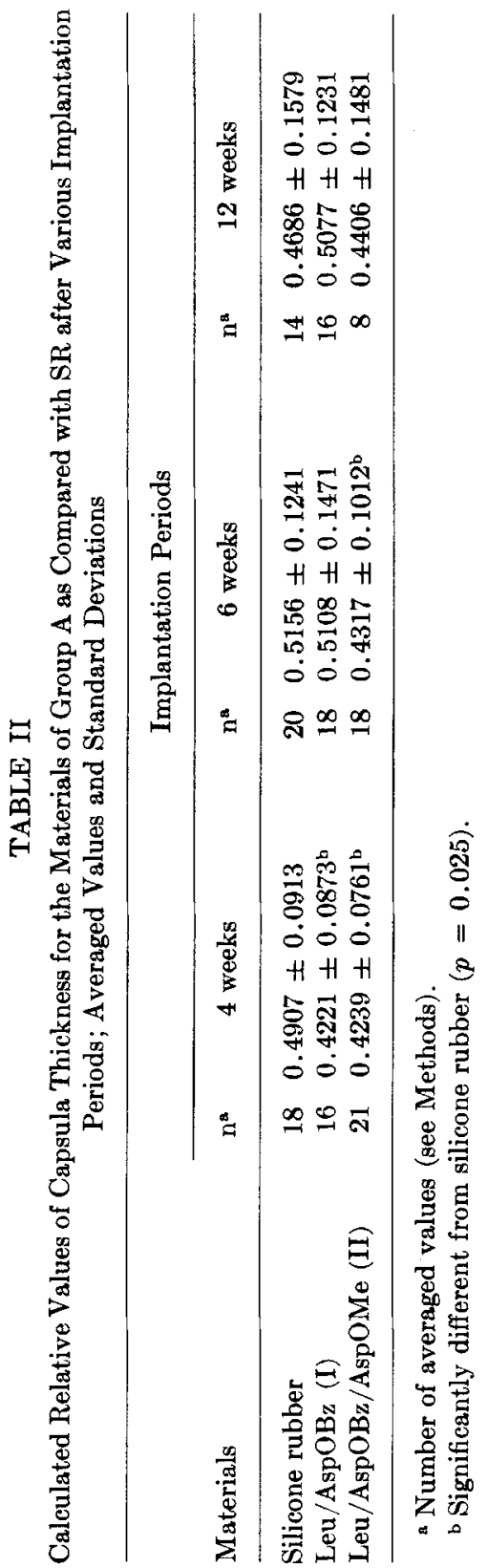




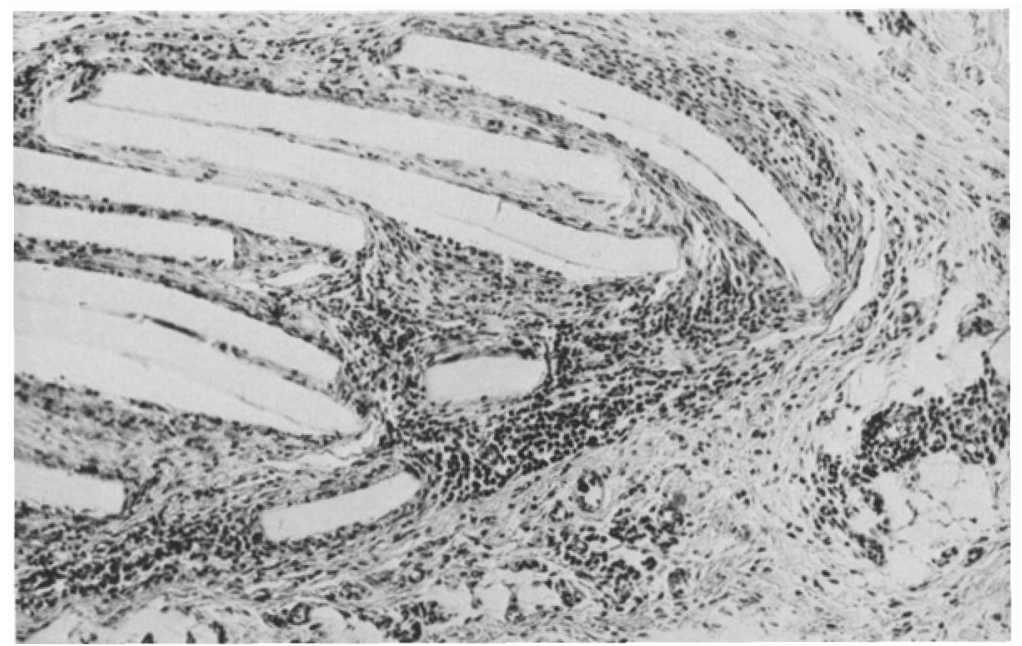

Fig. 4. Microscopic examination $(144 \times)$ of a biopsy taken after 6 weeks of Leu/AspOBz/AspOH (18 mole \% AspOH). Multiple fragments of broken and split material are surrounded by fibroblasts, macrophages, and giant cells. Infiltration of lymphocytes and plasma cells is also apparent.

process as described for group A was observed but fewer fibroblasts and additional numerous macrophages and giant cells surrounded the fragments of the materials (Fig. 5).

\section{Group C}

Because of the fast degradation of the materials in this group, the implant site could rarely be identified and a smaller amount of examinable slices were obtained. In those slices, 3 and 7 days after implantation, small remnants of desintegrated materials were surrounded by numerous fibroblasts and macrophages, often accompanied by an extensive area consisting of polymorphonuclear leukocytes and erythrocytes (Fig. 6). No necrosis was ever seen. Biopsies, taken at a later stage in areas of brownish tissue, never showed any peculiarity.

\section{DISCUSSION}

\section{Biodegradability}

The degradation process of polymeric materials in vivo depends not only on the chemical composition of the implant but also on its 


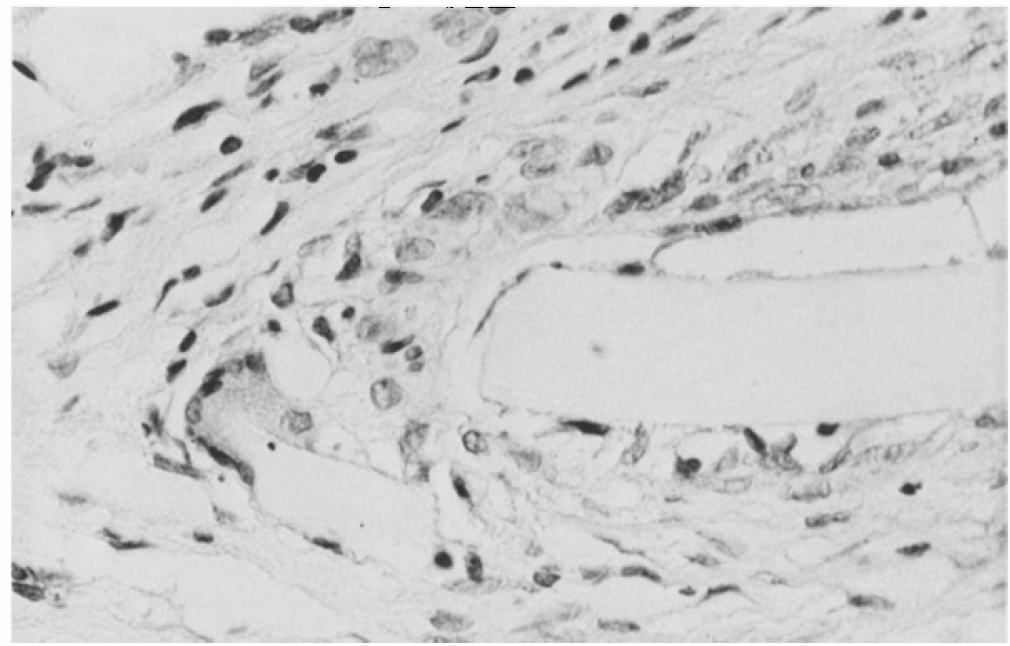

Fig. 5. Microscopic examination $(575 \times)$ of a biopsy taken after 6 weeks of Leu/AspOBz/ AspOH (25 mole \% AspOH), showing phagocytosis of tiny fragments by macrophages and giant cells.

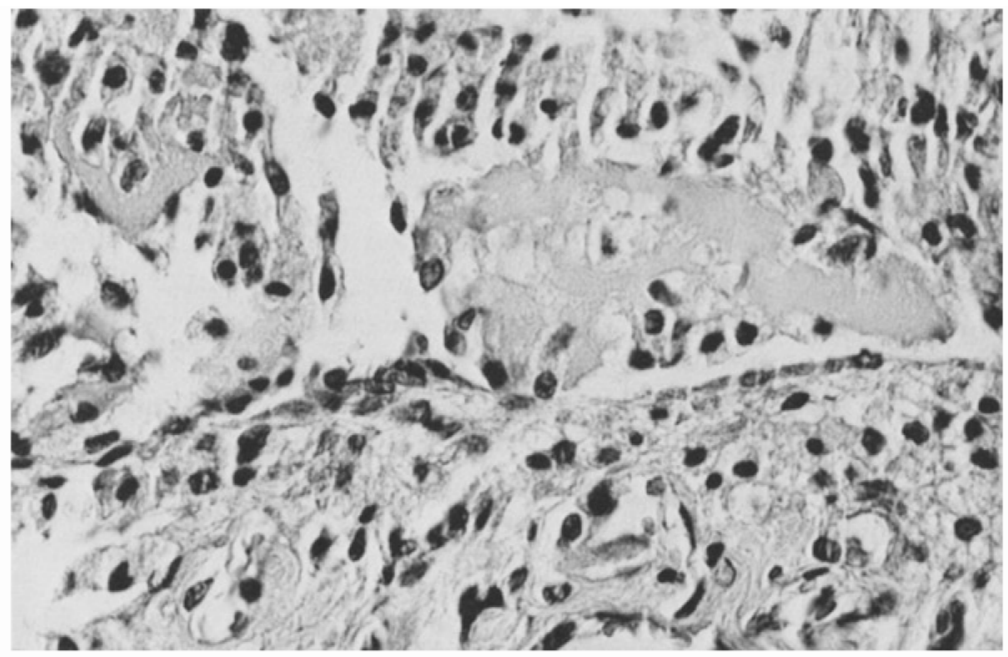

Fig. 6. Microscopic examination $(575 \times)$ of a biopsy taken after 1 week of Leu/AspOBz/AspOH (40 mole \% AspOH), showing remnants of disintegrated material surrounded by fibroblasts and macrophages. 
shape, physical structure, the implantation site, and the experimental animal used. In general, polymeric materials can be absorbed by such processes as dissolution, enzymatic degradation, and hydrolysis.

It is often very difficult to distinguish between the relative importance of these processes when an implanted material degrades. Frazza and Schmidt ${ }^{8}$ have investigated a variety of materials with respect to their biodegradability. Poly(ethylene oxide) strips, soluble in water, disappeared after 90 days implantation in rabbits. On the other hand, poly(vinyl alcohol), soluble in saline, could be recollected from the implant site after 90 days. The authors speculate that the initially dissolved polymer triggers a rapid foreign-body response which retards further dissolution.

In the absorption process of water- and saline-soluble polymers in animals, the dissolution of the material might play a dominant role. The same authors further investigated poly(glycolic acid); this product is not soluble in saline, but is absorbed slowly when implanted subcutaneously in rats. This process is most likely governed by hydrolysis, which may be aided by enzymatic catalysis. The absorption of poly(lactic acid), ${ }^{9}$ poly (glycolic acid), ${ }^{10}$ and nylon ${ }^{11}$ can all be described by the same process. It has been suggested that proteolytic enzymes play a role in the in vivo absorption of catgut ${ }^{12}$ and $\operatorname{poly}(\alpha$-amino acids $){ }^{13}$

Generally, the absorption of polymers in the body is facilitated when hydrolyzable linkages are available. ${ }^{14}$ The purpose of this study was to evaluate the effect of an increase in hydrophilicity of a series of poly ( $\alpha$-amino acids) on the rate of absorption and tissue reaction when these materials are subcutaneously implanted in rats.

In all experiments, disks of approximately the same size were used. All polymers consisted of the same chemical units: L-leucine, $\beta$-benzyl$\mathrm{L}$-aspartate, $\beta$-methyl-L-aspartate, and $\mathrm{L}$-aspartic acid. Only the relative composition of the polymers varied. The increase of the mole \% of $\mathrm{L}$-aspartic acid in the copolymers was accompanied by an increase of hydrophilicity. When the polymers III were converted into the sodium salt derivatives IV, the polymers became more swollen (increase in water uptake) upon contact with water.

\section{Group A}

Of the polymers in this group (Leu/AspLBz, I; Leu/AspOBz/ AspOMe II), macroscopically and microscopically no changes were 
observed 12 weeks after implantation (Fig. 1) and it was concluded that they were not or were only very slowly absorbed. The relative hydrophobic character of these materials prevented the uptake of appreciable amounts of water. In this case, hydrolysis and the action of proteolytic enzymes was restricted. These results correspond with the results of in vitro degradation experiments, where films of I were treated with the proteolytic enzymes trypsin $(\mathrm{pH}$ 8.0-8.1), $\alpha$-chymotrypsin ( $\mathrm{pH} 8.0$ ), and pepsin ( $\mathrm{pH} \mathrm{2.3)} \mathrm{in} \mathrm{buffered}$ solutions. ${ }^{15}$ Both coulometric and weight-loss measurements indicate very slow or no degradation.

\section{Group B}

The polymers of this group showed a slow absorption within the time of observation. The results do not indicate that within this group an increase in the mole \% of L-aspartic acid in polymers III leads to an increased absorption rate. Furthermore, the experiments with the sodium salt derivatives (IV, 0.18, 0.25) did not show a distinct increase in absorption rate as compared to the aspartic acid precursors (III).

These results show that the increased hydrophilicity of the copolymers III $(18,25$, and 35 mole $\%$ of L-aspartic acid) and IV (18 and 25 mole \% of L-aspartic acid) with respect to the hydrophobic copolymers I and II allows the degradation process to occur. However, the time of observation has to be extended in order to determine the time intervals of complete absorption of the materials of this group. Again, these results agree with earlier in vitro degradation experiments of IV ( 25 mole $\%$ of L-aspartic acid) using $\alpha$-chymotrypsin and trypsin at $\mathrm{pH}$ 8.0. Coulometric and weight-loss measurements indicate a distinct biodegradation rate. ${ }^{15}$

\section{Group C}

The polymers of this group were absorbed very quickly. Members of series III (40, 50, and 60 mole $\%$ of L-aspartic acid) were not soluble in saline, but they did dissolve in buffered saline solution. This was caused by conversion of the acid groups into the sodium salt derivatives. It is believed that the rapid absorption of the implants of this group could be explained by the conversion of the acid into the salt derivatives during implantation followed by dissolution.

Anderson et al. ${ }^{13}$ have carried out some studies with a series of copolymers of L-leucine (Leu), $\gamma$-benzyl-L-glutamate (GluOBz), and 
L-glutamic acid (GluOH) implanted subcutaneously in rats. These authors showed that the polymer Leu/GluOH (50 mole \% of GluOH) was still present 14 days after implantation. The polymers of group $\mathrm{C}$ in our series Leu/AspOBz/AspOH (III, 0.40, 0.50, and $0.60)$ macroscopically were absorbed within $24 \mathrm{hr}$ and 1 week. It can be concluded that the use of L-aspartic acid instead of L-glutamic acid in this series of copolymers increases their solubility when implanted subcutaneously in rats.

\section{Tissue Reaction}

The same division in groups $\mathrm{A}, \mathrm{B}$, and $\mathrm{C}$ is also used in the histological evaluation because the most important differences in tissue reaction between the copolymers correspond with their rate of degradation.

\section{Group A}

Microscopically, in general, no distinct differences were seen between the cellular pattern in the surrounding tissue of SR and the copolymers I and II. This reaction corresponds with the described tissue reaction caused by a number of biocompatible materials such as Teflon, ${ }^{16}$ silicone rubber, ${ }^{17}$ and Hydron. ${ }^{18}$ However, in our experiments, the amount of polyhedric cells in the inner layer of the capsula of SR is more pronounced than in the copolymers. These polyhedric cells are described as macrophages. ${ }^{17}$ This would suggest a greater effect of the SR material on the surrounding tissue. This could be either chemical in nature or caused by mechanical injury due to a greater mobility of the sample in the capsula. This latter possibility is in agreement with the observation that the capsula of SR is not attached to the material in contrast to the copolymers. An increase of the amount of macrophages is also seen around the edges of the samples where mechanical stresses are primarily expected. However, the importance of this observation remains as yet questionable.

The measurements of capsula thickness recently used as a quantitative parameter ${ }^{19-21}$ in implant studies also indicate a lesser reaction of the copolymers upon the surrounding tissues in the first months as compared to the control SR. However, at the end stage after 12 weeks, no significant differences are observed anymore between the copolymers and SR. Therefore, in our study the biocompatibility of these copolymers is at least comparable to that of SR. 


\section{Group $B$}

The tissue reaction of these biodegradable materials differed to a certain extent from those of the nondegradable group A. Eosinophilic leucocytes occurred more frequently. The numerous macrophages and giant cells together with the decrease of size of the materials indicate phagocytosis. The occurrence of lymphocytes with plasma cells suggests a more specific reaction against the materials. ${ }^{22}$ The histological picture resembles the one described for catgut. ${ }^{3,23}$ This observation points to the possibility of antigenecity of these copolymers. A further investigation in that direction is needed to demonstrate the nature and the importance of this observation.

The capsula thickness of these degradable materials could not be measured in a standard way and quantitative comparison to the other materials could not be obtained. However, the capsula thickness around the fragments of the materials is certainly no more apparent than those of the control SR. In this regard, those copolymers are certainly less reactive as compared to catgut.

\section{Group $C$}

The fast absorption of these materials caused a temporary inflammation, most likely of chemical nature. This was probably not due to the acid compounds of the material because in vitro experiments reveal that dissolution is only possible in a buffered saline solution. Perhaps dissolution of the materials occurs under hypertonic conditions or toxic concentrations, causing inflammation. Hyperemia and hemorrhage were observed only within the first week of implantation but disappeared without any residual effects. Remnants of the materials were observed only until 1 week after implantation.

\section{CONCLUSIONS}

After the subcutaneous implantation of disks of a series of copolymers of L-leucine, L-aspartic acid esters, and L-aspartic acid in rats, we can draw the following conclusions:

1) Three groups of materials with a varying mole \% of L-aspartic acid $(\mathrm{A}, 0 \% ; \mathrm{B}, 18,25$, and $35 \%$; and $\mathrm{C}, 40,50$, and $60 \%$ ) can be distinguished. The hydrophobic materials of group A do not 
show degradation after 12 weeks. Somewhat more hydrophilic materials of group B reveal a gradual reduction in size of the samples, but after 12 weeks these are still present. Hydrophilic materials of group C disappear within $24 \mathrm{hr}$.

2) The tissue reactions caused by the materials in groups A, B, and $\mathrm{C}$ were studied and compared with silicone rubber. The tissue reaction caused by the polymers of group A resembles that of silicone rubber, but the capsula is fixed to these materials in contrast to silicone rubber. In group $\mathrm{B}$, the tissue reaction is marked by the occurrence of lymphocytes and plasma cells and an increased amount of macrophages, foreign-body giant cells, and eosinophilic leukocytes. The fast absorption of the materials of group $\mathrm{C}$ causes a temporary chemical inflammation.

The authors wish to thank Prof. Ph.J. Hoedemaeker, Department of Pathology, University Hospital, Groningen, for his technical help, and Ms. Babs van Leeuwen for her excellent assistance.

\section{References}

1. F. Leonard, R. K. Kulkarni, J. Nelson, and G. Brandes, J. Biomed. Mater. Res., 1, 3 (1967).

2. K. C. Pani, G. Gladieux, G. Brandes, R. K. Kulkarni, and F. Leonard, Surgery, 63, 481 (1968).

3. A. R. Katz and R. J. Turner, Surg. Gynecol. Obstet., 131, 701 (1970).

4. T. Miyamae, S. Mori, and Y. Takeda, U.S. Pat. 3, 371,069 (February 27, 1968).

5. T. M. Jackanicz, H. A. Nash, D. L. Wise, and J. B. Gregory, Contraception, 8, 227 (1973).

6. W. L. Sederel, A. Bantjes, and J. Feijen, Polymer, 16, 735 (1975).

7. E. M. Bradbury, B. G. Carpenter, and H. Goldman, Biopolymers, 6, 837 (1968).

8. E. J. Frazza and E. E. Schmitt, J. Biomed. Mater. Res. Symposium No. 1, 43 (1971).

9. R. K. Kulkarni, E. G. Moore, A. F. Hegyeli, and F. Leonard, J. Biomed. Mater. Res., 5, 169 (1971).

10. J. M. Brady, D. E. Cutright, R. A. Miller, G. C. Battistone, and E. E. Hunsuck, J. Biomed. Mater. Res., 7, 155 (1973).

11. J. T. Scales, Acta Orthop. Scand., 27, 13 (1957).

12. R. A. Willis, Principles of Pathology, 2nd ed., Butterworths, London, 1961.

13. J. M. Anderson, D. F. Gibbens, R. L. Martin, A. Hiltner, and R. Woods, J. Biomed. Mater. Res. Symp. No. 5, 197 (1974).

14. D. F. Williams and R. Roaf, Implants in Surgery, W. B. Saunders Comp. Ltd., London, 1973, p. 189. 
15. J. Feijen, W. L. Sederel, T. Beugeling, and A. Bantjes, Proc. Eur. Soc. Artif. Organs, 1, 37 (1975).

16. H. H. LeVeen and J. R. Barberis, Ann Surg., 129, 74 (1949).

17. P. Hernández-Láuregui, Surgery, 75, 631 (1974).

18. J. Kopecek, L. Sprincl, H. Bazilová, and J. Vacik, J. Biomed. Mater. Res., 7, 111 (1973).

19. P. G. Laing, A. B. Ferguson, and E. S. Hodge, J. Biomed. Mater. Res., 1, 135 (1967).

20. R. D. Tetik, J. O. Galante, and W. Rostoker, J. Biomed. Mater. Res., 8, 231 (1974).

21. I. R. Toranto, K. E. Sayler, and W. B. Nickell, J. Biomed. Mater. Res. Symp. No. 5, 127 (1974).

22. D. E. Ocumpaugh and H. L. Lee, Biomedical Polymers, A. Rembaum and M. Shen, Eds., Dekker, New York, 1971, p. 116.

23. W. R. Sewell, J. Wiland, and B. N. Craver, Surg. Gynecol. Obstet., 100, 483 (1955).

Received May 13, 1976

Revised August 9, 1976 